\title{
Economic Consequences of Section Transfers in Japan: Change in Investor Base
}

\author{
Abo Rodrigue Majoie ${ }^{1}$
}

\begin{abstract}
Transfer of stocks to a more regulated section within the same stock exchange is a quasi-natural experiment that enhances the investor base of companies. The purpose of this paper is to examine for the first time this investor base change and its priceimpact. Considering the Japanese Exchange Group merger in 2012 and its structural amendments, the author uses a final sample of 181 firms between 2014-2019. An event study methodology is used to examine the abnormal returns and trading activity in relation to the investor base change proxy. The study also uses robust MM regression analysis to investigate whether the expected price-impact has is temporary or permanent. The results demonstrate that companies that had the largest positive shift in investor base also experienced the largest positive abnormal returns $(+3.74 \%)$ and volume gains. Crucially, the author found no evidence of reversal of this price-impact, inconsistent with the price-pressure hypothesis. Instead, the increase in stock prices caused by section transfer to a more regulated section seems to be permanent.
\end{abstract}

Keywords: Section transfers, More regulated section, TSE1, TSE2, Investor Base Change, Permanent price-impact.

${ }^{1}$ Graduate School of Economics, Osaka University, PHD Candidate.

Article Info: Received: February 16, 2021. Revised: March 2, 2021.

Published online: March 19, 2021. 


\section{Introduction}

For decades, SECTION TRANSFERS (ST) to a more regulated section have offered companies' managers a way to upgrade the listing of their stocks within the same stock exchange. Similarly, ST to a less regulated section provided securities regulators with the opportunity to downgrade stock listings in case of noncompliance with the established section requirements. Studies have proven that ST to a more regulated section have a tremendous positive impact on the value of the firms and their liquidity levels. Still, some companies decide not to transfer or sometimes transfer to a less-regulated section as observed in the paper of Campbell and Tabner (2014). A natural question arises: Are all ST beneficial to companies? Transfer to a more regulated section presents several advantages. Nevertheless, to transfer on any section the company has to fulfill a certain number of new requirements. Each section has different listing requirements corresponding to its regulation level (Cisse and Fontaine, 2015). Predictably, the advantages were found to be positively associated with the regulation level of the sections (Campbell and Tabner, 2014). Among these advantages, the most cited are: increased investor recognition associated with widening the investor base and increased information availability; easiness in raising capital from the public, increased visibility and trustworthiness; increased liquidity levels. On the other hand, these advantages are not without some inconveniences such as extra disclosure of important information and the costs of the disclosure; reduction of decision-making power and control of management; fees associated with the new listing process.

Despite these clear inconveniences, on numerous stock exchanges, companies persistently strive to undergo another entire listing process and transfer to a more regulated section or higher quality section within the same stock exchange. As mentioned before, the higher the quality of the section is, the better the advantages and the stringent the requirements or inconveniences are expected to be. One can argue therefore that the profit earned by companies from transferring into a more regulated section outshines the inconveniences and costs related to the transfer process. And, since those advantages are closely related to the regulation level of the sections towards which the companies transfer, we find therefore important to investigate the economic consequences of ST as per the regulation level or quality of the destination section.

In this paper, we are interested in one in particular: the increase in the investor base. By transferring to a more regulated section, stocks are automatically exposed to the new section's pool of investors or a new level of investor recognition. And this pool of investors may largely differ from one section to another including the trading intensity of the respective market participants. These differences can be explained by several factors in which the most cited are:

a. the listing requirements,

b. the level of investor protection,

c. the information availability on stocks. 
For instance, Campbell and Tabner (2014) revealed that companies that transferred to the UK's most regulated section:

Official List of the London Stock Exchange (LSE) bonded themselves with much more stringent performance obligations as compared to the ones that transferred to the Alternative Investment Market (AIM). As a result, investors felt more secured and protected because of these performance obligations and invested more in the LSE Official List shares instead of AIM shares. Merton (1987) supported in his model of capital market equilibrium and information availability that investors tend to negotiate stocks on which they have information. The disclosure requirements on the LSE Official List are more stringent than those of the AIM. It is foreseeable that investors might be more informed about stocks listed on the LSE Official List. Merton (1987) suggested that any operation led by the companies' managers to increase the visibility of the stocks and subsequently increase the information availability must widen the size of the investor base. Transferring to a more regulated section is seen as a consistent path to increase investor recognition and investor base (Cisse and Fontaine, 2015). Again, Merton (1987) through his investor recognition hypothesis stipulated that such increases in investor base are not without economic consequences including increased firm's value, reduction of the cost of capital, and efficient risk-sharing. All translating into an increase in liquidity. Since the listing requirements in terms of information availability and performance are largely dependent on the sections' regulation level (Cisse and Fontaine, 205; Campbell and Tabner, 2014), we also supposed that the economic consequences stipulated by Merton (1987) may differ according to the regulation level of the section towards which the transfers are operated. In this paper, we focus exclusively on the extent to which the investor base changes and its economic consequences. It is factual that the first section of the Tokyo Stock Exchange (TSE 1) is by far the most prestigious/more regulated section of the Japanese market. Intuitively the number of investors trading on the TSE might be comparatively larger than any other section. However, one can imagine that it is a challenge to systematically assume that companies that transfer to the TSE 1 would be more recognized by investors and have the largest increase in terms of the investor base. Interestingly, the uniqueness of our sample allows us to robustly support our intuition. All companies that transfer to the TSE 1 are instantly added to one of, if not the largest index in Japan: the TOPIX. This situation is not atypical and occurs in some worldwide stock exchanges in which stocks listed in the most regulated section constitute if not all, the largest portion of major indexes. For instance, the Official List (main section) of the LSE and the FTSE100 index; the "Premier Marché" of the Paris Stock exchange, and the CAC40 index. In our sample, the remaining ST towards the second section of the Tokyo Stock Exchange (TSE 2) do not have the same experience. Indexes inclusions studies have established that the observed immediate increase in stock prices around the inclusion day is caused by a demand pressure from an increased investor base (Harris and Gurel, 1986; Nakaguma et al., 2003). We, therefore, found it adequate to use the singularity of our sample and consider the inclusion of the transferred stocks into the TOPIX as a dummy proxy 
that demonstrates a major increase in the investor base for certain stocks in our sample. In other terms, we assumed that firms that transferred to the TSE 1 and joined the TOPIX index experienced the highest growth in terms of investor base level.

We excavated more on the investor base change and its economic consequences principally on the stocks' abnormal returns and volumes after the ST execution day. For recall, relevant existing studies established the presence of positive abnormal returns around the transfer day (Lamba and Ariff, 1997; Campbell and Tabner, 2014), not knowing whether these abnormal returns will revert completely after the transfer. In the latter part of our study, we investigated whether the observed positive abnormal returns have a temporary or permanent effect. In other words, whether the stock prices maintain their increment after the ST execution day. According to the Price Pressure Hypothesis (PPH), the subsequent rise of stocks price caused by an increased demand will fully revert to their initial prices due to the auto-correction of market frictions (Harris and Gurel, 1986). On the other side, the downward slope demand curve stands for a gradual upward shift of stock prices to eliminate the excess demand (Bagwell, 1991, 1992; Kaul et al., 2000). Once a company transfers to a more regulated section, the demand for the stock is expected to permanently increase as the investor base increases. We test whether this excess demand translates into a permanent increase in prices.

This paper makes a great contribution to the literature. Most studies so far identified the liquidity level of companies before the transfer event as the main explanatory factor of abnormal returns. This research adds to the literature by studying the investor base change caused by ST and its economic consequences mainly on stock returns and trading volumes as suggested by Merton (1987). Additionally, it investigates whether ST have a permanent price-impact on stocks. Sample-wise, it differentiates itself from prior related studies. In contrast to the study of Lamba and Ariff (1997) on ST in Japan, it uses a much larger and variate sample that includes a new set of sections such as the JASDAQ and MOTHERS. This is possible because of the recent merger of the Japanese Exchange merger in 2012. Not only, we have now a much larger and variate sample, but this merger enables us to systematically control for the same legal, trading technology, rules, and regulations for a larger set of sections within the same stock exchange. Lamba and Ariff (1997) could not do the same. In terms of methodology, this paper innovates in its computation of abnormal returns. Contrary to other studies (Baker and Edelman, 1990; Lamba and Ariff; 1997), we use in addition to the market index the average returns of comparable firms as a benchmark to estimate abnormal returns. The reason behind this choice is to consider important factors overlooked by former studies such as the size, the industry, the market to book ratio, sales, and environment. According to (Fama and French, 1992, 1995; Fama and Kenneth, 1993; Carhart, 1997) these factors are important to analyze stock returns.

Our results confirmed that ST to a more regulated section generate positive abnormal returns and increase volumes in general. However, the extent of these positive effects is positively correlated with the extent to which the investor base 
increases. For instance, during our whole transfer event (30 days prior and 30 days after the ST execution day; $[-30 ;+30]$ days), the average abnormal returns were significantly positive $(+3.74 \%)$ for companies that experienced the largest positive shift in their investor base by transferring to the TSE1. This positive reaction mainly occurred 4 weeks before the execution day. On the other hand, the same was negative for other transferred companies (-4.48\%). These results were robust while using the comparable sample returns as a benchmark to compute the abnormal returns. Consistent with the demand pressure, we also noticed an increase of more than four times the trading volumes stocks that transferred to the TSE 1. Again, stocks that transferred to the TSE 2 have a comparatively lower increase in terms of volume ratios. We also found no evidence of full reversal of the initial positive abnormal returns after the transfer day, inconsistent therefore with the pressure hypothesis. This suggests that ST might have a permanent price-impact on stocks. The remainder of the paper is chronologically organized as follows. Next, in section 2 the literature review brings out the theoretical and empirical background discussing the stock returns behavior around ST. In section 3, the data is presented. The methodology, findings are detailed and interpreted in section 4. Finally, we present a summary of the findings and discussions in section 5 .

\section{Preliminary Notes}

\subsection{Background of the study}

\subsubsection{Reasons and expectations of ST}

As discussed earlier, some companies may fulfill all requirements to transfer in a more regulated section but decide not to. This explicitly exhibits the voluntary nature of ST. Most ST necessitate that the applicant company fills voluntarily the relevant forms and submit them to the stock exchange regulators for consideration. Regulators in return must ensure that the applicant (company) fulfills all requirements to be reassigned into the requested section. For instance, Japanese companies listed in the Mothers and JASDAQ sections should meet stringent requirements to list in the most prestigious $1^{\text {st }}$ section (TSE1) of the Japanese Exchange (JPX). To cite a few, companies must:

- have 2200 or more shareholders.

- have 20000 units or more in terms of tradable shares.

- The number of tradable shares should be at least $35 \%$ of the outstanding number of shares capitalized at 2 Million Yen or more.

- The trading volume of the last 3 months should be at least 200 trading units.

- The profit of the last two years should be at least 500 Million Yen with 10000 Million as sales for the last year.

- Established an entrusted shareholder agent designated by the regulators.

This thorough process does not come without costs. From listing fees, auditors' fees, and so on, companies have to bear several costs to transfer. It seems logical that the gains expected from ST must be greater than the costs incurred. More specifically, 
Cisse and Fontaine (2015) extracted from prospectuses the key reasons that lead managers to decide to transfer to a more regulated section. These reasons are: to increase the company's visibility, to increase the investor base and investor recognition level, to enhance the company's credibility towards the stakeholders, to improve the liquidity, to fund expansion or growth projects with greater access to capital, and to reduce the cost of capital.

Indeed, these reasons are very attractive to companies. In the same order, investors may also see ST to a more regulated section as an opportunity. Since companies undergo strict scrutiny by the exchange regulators, investors can entrust ST as a filter for companies having better prospects. When considered, ST are expected to generate a positive reaction from investors. Besides, it is important to note that the requirements above are much lighter when companies aim to list in the $2^{\text {nd }}$ section of the JPX. Thus, logically we can assume that the market reaction must be more favorable towards companies transferring into the $1^{\text {st }}$ section as compared to companies transferring in the $2^{\text {nd }}$ section.

\subsubsection{Section Transfers in Japan; increased investor base and reduction of information asymmetry}

In Japan, the TSE1 is the more regulated section with the highest market capitalization. Uno et al. (2004) proved that the market participants in the TSE1 section differ largely from those in other sections. They ascertained that when stocks are transferred to the TSE1 section, a large number of institutional/foreign investors are added to the pre-existing investor base. They supported that these institutional and foreign investors are mainly attracted by companies listed in the TSE1 as they are less unpredictable since they had to go through and maintain stringent requirements to remain listed in the TSE 1. Also, since most funds are dealing increasingly with passive investment strategies, they are keener to invest in the most reliable securities.

Moreover, ST towards TSE1 may generate a sudden interest of media and technical analysts about the transferring company. And this increased interest is supposed to convert into an increase of relevant information, increasing the number of informed investors. Concerning the disclosure of information, rule 207(4) of the JPX securities law enforces that the company applicant aiming to transfer to the TSE1 should be in a position to disclose corporate information appropriately. The same is not enforced for TSE 2.

\subsection{Investor base level proxy}

As mentioned earlier, the investor base of stocks is expected to change according to the regulation level of the section towards which they transfer. We cannot directly assess the change in investor base caused by the ST. Similarly, to King and Segal (2006), we use the inclusion into the TOPIX occurring simultaneously for all stocks transferring to the TSE 1 to measure this change in investor base level. In their study, they supported that inclusion into a major index would boost the visibility of firms, 
increase their shareholder base domestically. Main indexes in stock exchanges represent the top companies with the highest capitalization within these stock exchanges. And these firms are mostly listed in the more regulated section of the stock exchange. For instance, the firms constituting the CAC 40 index are exclusively listed in the more regulated section "Premier Marché" of the Paris Stock Exchange. Similarly, the FTSE 100 Index in the UK includes exclusively companies listed in the most regulated section: Official List of the London Stock Exchange with the highest market capitalization. In Japan, the TOPIX also represents entirely the stocks listed in the most regulated section of the JPX: TSE1. Arguably, free float weight-adjusted market capitalization major indexes such as TOPIX, FTSE 100, and CAC 40 are close representative of the most regulated section in their respective stock exchange.

On the other side, studies have demonstrated that inclusion in these indexes tremendously changes the stock investor base. This is because once added large market participants automatically buy and hold these stocks to shadow the indexes' performance (Nakaguma et al., 2003). Recent studies on the growing use of passive investment seeking to match, not to beat the return of major indexes stipulated that large funds intend to mimic the index by buying exclusively in a passive manner all stocks included in major indexes (Anadu et al., 2018). Foreign investors also benchmark their operations based on renowned indexes (Hattangadi and Kelkar, 2016).

With the above, we justify our assumption that while transferring to the most regulated section of a stock exchange such as the TSE 1, stocks undergo a relatively larger increase in investor base as compared to other transfers. The statistics in Table 2 supports our choice, as it can be observed that companies that transferred to the TSE 1 have the highest percentage of shares held by institutional investors $(28.3 \%)$ as compared to $(13.25 \%)$ for other transfers.

\section{Review of Literature and Hypotheses}

As mentioned earlier, there are few studies about ST. Baker and Edelman (1990) studied 278 companies that transferred from the OTC (Over the Counter) NASDAQ to the NASDAQ's National Market System (NMS). They observed that abnormal returns three weeks before the transfer day were significantly positive. Contrasting with other studies, the abnormal returns after the transfer were not statistically significant. They argued that if the market is efficient, abnormal returns after the transfer should not be statistically significant. Cisse and Fontaine (2015) on their side focused on a relatively small sample of 71 French stocks. They found a positive market reaction around the transfer, especially for low-liquid companies. This positive reaction weakened strongly after the transfer day.

Concerning ST in Japan, they are solely executed amongst four sections. The first section (TSE 1) and the second section (TSE 2) are referred to as the "main markets"; with TSE 1 the more regulated and prestigious section. Both together consist respectively of all leading large and second-tier companies. They represent the 
largest sections in terms of size and liquidity. The JASDAQ section including JASDAQ Growth, JASDAQ Standard and the Mothers section abound of companies with high growth potential. Companies listed there, generally aim to transfer progressively in the TSE 2 and further the TSE1 section. For instance, Lamba and Ariff (1997) focused exclusively on transfers from the TSE2 to the TSE1. Their results also confirmed the presence of significant positive abnormal returns before the transfer day. These were particularly higher for low-liquid companies. They also observed a significant increase in excess trading volumes. They suggested that dominant foreign and large domestic mutual funds operating mainly in the first section persistently buy the new transferred stocks. Uno et al., (2004) supported that the voluntary decision to transfer to the most prestigious section is motivated by the desire of companies to increase their shareholder base. Otherwise, by crossing all potential bonding costs (Kadlec and McConnell, 1994) companies may in return attract more investors and boost their liquidity levels (Amihud and Mendelson, 1986). Pragmatically, ST to a more regulated section increase the liquidity levels and stock prices partially due to an increased investor base.

However, to investigate the relationship between the investor base change and the market reaction on stock prices and volumes can be quite challenging. The challenge lies in finding a proxy that can measure the change of the firm's investor base per the regulation level of the destination section. As discussed earlier, the change in investor base might be positively correlated to the regulation level of the section. For instance, Uno et al., (2004) have demonstrated that transferring towards the top section of a stock exchange increases much significantly the shareholder base of firms. In our particular case, ST to the top section of the JPX (TSE1) are concurrently associated with the inclusion into the TOPIX index. This situation amplifies the fact that the change in investor base for these transfers would be relatively larger because index inclusion substantially generates an increase in investor base (Nakaguma et al., 2003). Thus, based on Merton's (1987) investor recognition hypothesis, the extent to which the stock prices rise would unlikely to be the same for stocks that transfer to the TSE 1. In this study, we use the index inclusion into the TOPIX as a proxy for the superiority of change in investor base level concerning companies that transfer to the TSE1. We designed our following first hypothesis:

H01: The increase in stock prices are significantly higher for stocks that transfer to the most regulated section and encounter the largest increase in terms of the investor base.

Moreover, researchers commonly agreed on the presence of negative abnormal returns after the transfer (Lamba and Ariff, 1997; Baker and Edelman, 1990; Cisse and Fontaine, 2012; Campbell, 2014; Uno et al., 2004), but did not address the behavior of these abnormal returns after the transfer. Whether these negative abnormal returns lead to a full reversal of the initial positive abnormal returns, is the second motivation of our study. As assumed earlier, ST towards the most 
regulated section TSE1 generate a comparatively a much larger increase in investor base. This change in investor base might lead to a demand shock around the ST execution day. The debate on whether demand shock results in temporary price pressure or has a permanent effect has been heavily conducted (Harris and Gurel, 1986; Jain et al., 1987). Consistent with EMH, some supported that the immediate rise in stock prices is short-termed due to auto-correction of market frictions by the arbitrage forces, flattening the demand curve (Harris and Gurel, 1986). On the other hand, studies supported a gradual and permanent shift in stock prices (Jain et al., 2019). We can observe that literature conflicts on either there is a temporary priceimpact or a permanent price-impact. Since ST are not likely to change temporarily the investor base, but permanently, we could design the following hypothesis:

Ho2: Since ST to a more regulated section lead to a permanent increase in investor base, the stock prices will permanently increase.

\section{Data}

In Table 1, our initial sample consisted of all 478 Japanese companies that transferred from January 2015 to July 2019. During our sample period, only one company transferred from a more regulated section to a less regulated section due to liabilities in excess of assets. Moreover, companies listed in TSE 2 can only transfer to the next more regulated section: TSE 1 . To ensure the homogeneity of our data we excluded these companies and focused on those that had both the options to either transfer to the first section (TSE 1) or the second section (TSE 2). This reduced the data to 287 companies. We further excluded 23 companies whose dates of transfers were not trading days. 
Table 1: Section Transfers on the Japanese Exchange Group (JPX) between January 2015 and July 2019.

\begin{tabular}{|l|c|c|c|c|c|c|}
\hline $\begin{array}{c}\text { Origin section } \\
\text { before the transfer }\end{array}$ & $\mathbf{2 0 1 5}$ & $\mathbf{2 0 1 6}$ & $\mathbf{2 0 1 7}$ & $\mathbf{2 0 1 8}$ & $\mathbf{2 0 1 9}$ & TOTAL \\
\hline \multicolumn{7}{|c|}{ Destination: TSE1 } \\
\hline TSE2 & 47 & 43 & 46 & 48 & 8 & 192 \\
\hline JASDAQ Standard & 17 & 6 & 1 & 3 & 4 & 31 \\
\hline JASDAQ Growth & 0 & 0 & 0 & 0 & 0 & 0 \\
\hline Mothers & 20 & 29 & 23 & 28 & 9 & 109 \\
\hline Sub-Total & 84 & 78 & 70 & 79 & 21 & 332 \\
\hline \multicolumn{7}{|c|}{ Destination: TSE2 } \\
\hline JASDAQ Standard & 27 & 22 & 19 & 20 & 5 & 93 \\
\hline JASDAQ Growth & 0 & 0 & 1 & 3 & 0 & 4 \\
\hline Mothers & 24 & 13 & 5 & 7 & 0 & 49 \\
\hline Sub-Total & 51 & 35 & 25 & 30 & 5 & 146 \\
\hline TOTAL & 135 & 113 & 95 & 109 & 26 & 478 \\
\hline
\end{tabular}

Notes: *TSE 1 is the first section of the JPX. TSE 2 is the second section of the JPX

This table presents the annual distribution of the section transfers' initial sample by origin and destination.

Also, to be maintained in the sample, companies were required to have not more than 10 missing daily returns and 5 consecutive missing daily returns during the whole period window $[-250 ;+30]$ days, day 0 being the ST execution day. After all adjustments, the total number of 181 companies were retained in the final sample. The daily trading volumes, trading values, closing-adjusted prices (i.e. season offerings, stock splits, and dividend payments), market capitalization, market-tobook ratios were obtained from the FINQUEST database. The data concerning the origin and destination sections of the ST along with the ST respective execution dates were obtained directly from the Japan Exchange Group official website. The data on the control sample was obtained from the EOL database. EOL database is a private Japanese data source that provides boutique matches for companies based on their industry, market capitalization, sales size, and listing sections. Stock returns and volume ratios were calculated using daily closing prices, stock trading volumes, and market trading volumes. 
Table 2: Summary Statistics of the Final Sample: 181 Companies

\begin{tabular}{|l|c|c|c|c|}
\hline Companies & $\begin{array}{c}\text { Average } \\
\text { Annual Growth }\end{array}$ & $\begin{array}{c}\text { Average } \\
\text { Annual } \\
\text { Ownership }\end{array}$ & $\begin{array}{c}\text { Size (Market } \\
\text { Capitalization } \\
\text { Million Yen) }\end{array}$ & $\begin{array}{c}\text { Average } \\
\text { Annual M/B } \\
\text { Ratio }\end{array}$ \\
\hline \multicolumn{5}{|c|}{ All Sample } \\
\hline All Transfers & 14.58967 & 24.75221 & 28100 & 7.0469 \\
\hline TSE 1 & 7.803696 & 28.33428 & 34700 & 8.131794 \\
\hline TSE 2 & 36.36791 & 13.25628 & 6970 & 3.565149 \\
\hline \multicolumn{5}{|c|}{ High-Liquid Companies } \\
\hline All Transfers & 17.87124 & 25.95157 & 27500 & 8.496679 \\
\hline TSE 1 & 7.736263 & 28.8202 & 31900 & 9.324019 \\
\hline TSE 2 & 63.47864 & 13.04273 & 760 & 4.77365 \\
\hline \multicolumn{5}{|c|}{ Low-Liquid Companies } \\
\hline All Transfers & 7.971833 & 22.3335 & 29400 & 4.123179 \\
\hline TSE 1 & 7.974872 & 27.10077 & 41900 & 5.105374 \\
\hline TSE 2 & 7.966191 & 13.48 & 6310 & 2.299101 \\
\hline
\end{tabular}

Notes: *Annual growth is computed using the sales revenues of the recent 3 years.

*Annual ownership represents the percentage of shares held by institutional investors after the transfer.

* Market capitalization is the capitalization of outstanding shares.

This table exhibits the average: annual growth, ownership of institutional investors, size and market-to-book ratio of companies before their transfers.

\section{Main Results}

\subsection{Positive market reaction}

To measure the price reaction caused by ST, we used the stocks' abnormal returns based on the daily adjusted-closing prices. We computed it as follows:

$$
R_{i t}=\ln \left(\frac{P_{i t}}{P_{i t-1}}\right)
$$

$R_{i t}$ is the return of each stock $i$ at day $t, P_{i t}$ the adjusted closing price of the stock $i$ at day $t$, and $P_{i t-1}$ the adjusted closing price of the same stock $i$ at day $t-1$.

Most researchers used the difference between the stock returns at time $t$ against the market index return. In this study, we estimated first the performance of the companies during our transfer event [-30;30] days. We chose this period because we assume that though the ST takes place on the execution day, investors may learn about the transfer a few weeks in advance. Also, the transfer approval is generally obtained one week (i.e. 5 trading days) before the execution; with some exceptions. We were unable to use the exact approval dates as we had no accurate information on some deferred approvals. We computed the CAPM parameters one year before the transfer (i.e. estimation window). To do so, we conducted a separate regression 
for each firm within the estimation window [-250; -31] days and saved the coefficients. Next, we used these coefficients to estimate the stock returns during our transfer event $[-30 ; 30]$ days; as if the stocks did not transfer. Thus, the classic abnormal returns computation was simply the difference of the stock returns at time $t$ against the estimated returns:

$$
\begin{aligned}
& A R_{i t}=R_{i t}-E R_{i t} \text { for } t \in[-30 ;+30] \\
& E R_{i t}=\alpha_{i}^{*}+\beta_{i}^{*} R_{m t}+\varepsilon_{i t} \text { for } t \in[-30 ;+30] \\
& \left(\alpha_{i}^{*} \text { and } \beta_{i}^{*} \text { are estimated over }[-250 ;-31] \text { period }\right)
\end{aligned}
$$

$R_{m t}$ is the overall market return. As mentioned earlier, we also used a comparable sample method, where the benchmark was the mean of the comparable stocks returns:

$$
E R_{i t}=\bar{R}_{i t}^{\text {CONTROL }}
$$

We notice that all ST in general had positive abnormal returns before the transfer day. In Table 3 and Table 4, we observe that the positive abnormal returns begin to be significant around the fifth $\left(5^{\text {th }}\right)$ day before the transfer with the highest peak on the $4^{\text {th }}$ day. 
Table 3: Average Abnormal Returns tests of significance using the mean of comparable stocks returns as benchmark.

\begin{tabular}{|c|c|c|c|c|c|c|c|c|c|}
\hline Days & \multicolumn{3}{|c|}{ All Transfers } & \multicolumn{3}{|c|}{ TSE 1} & \multicolumn{3}{|c|}{ TSE 2} \\
\hline & $\begin{array}{c}\text { Average } \\
\text { Abnormal } \\
\text { Returns } \\
\text { (AAR) }\end{array}$ & t-stat & Sig & $\mathbf{A A R}$ & t-stat & Sig & AAR & t-stat & Sig \\
\hline-30 & 0.00074 & 0.28939 & & 0.00263 & 0.81415 & & -0.00529 & -1.65322 & \\
\hline-29 & -0.00034 & -0.15216 & & 0.00014 & 0.04952 & & -0.00192 & -0.56553 & \\
\hline-28 & -0.00130 & -0.47146 & & -0.00179 & -0.53387 & & 0.00027 & 0.06189 & \\
\hline-27 & 0.00033 & 0.15207 & & 0.00268 & 1.04052 & & -0.00720 & -1.91077 & $* * *$ \\
\hline-26 & 0.00430 & 1.57556 & $*$ & 0.00292 & 0.98733 & & 0.00873 & 1.34311 & \\
\hline-25 & -0.00239 & -0.77802 & & -0.00035 & -0.10209 & & -0.00892 & -1.34286 & \\
\hline-24 & -0.00189 & -0.78074 & & -0.00273 & -0.99879 & & 0.00080 & 0.15414 & \\
\hline-23 & 0.00462 & 2.01136 & $* * *$ & 0.00613 & 2.35720 & $* * *$ & -0.00023 & -0.04793 & \\
\hline-22 & -0.00435 & -1.58170 & $*$ & -0.00602 & -1.76811 & $* *$ & 0.00098 & 0.25478 & \\
\hline-21 & -0.00014 & -0.05794 & & 0.00002 & 0.00562 & & -0.00065 & -0.19975 & \\
\hline-20 & -0.00309 & -1.18091 & & -0.00159 & -0.49191 & & -0.00791 & -2.16871 & $* * *$ \\
\hline-19 & -0.00122 & -0.44830 & & -0.00083 & -0.25336 & & -0.00247 & -0.53949 & \\
\hline-18 & -0.00343 & -1.34060 & & 0.00003 & 0.00926 & & -0.01453 & -2.62017 & \\
\hline-17 & 0.00389 & 1.58402 & $*$ & 0.00452 & 1.54938 & $*$ & 0.00188 & 0.42310 & \\
\hline-16 & -0.00068 & -0.29316 & & -0.00129 & -0.49606 & & 0.00127 & 0.25021 & \\
\hline-15 & -0.00039 & -0.12258 & & -0.00172 & -0.48259 & & 0.00385 & 0.53249 & \\
\hline-14 & 0.00184 & 0.52376 & & 0.00009 & 0.02391 & & 0.00746 & 0.80396 & \\
\hline-13 & 0.00015 & 0.05835 & & 0.00141 & 0.48159 & & -0.00386 & -0.63699 & \\
\hline-12 & -0.00191 & -0.75812 & & 0.00046 & 0.15909 & & -0.00950 & -1.86071 & $* *$ \\
\hline-11 & -0.00171 & -0.70496 & & -0.00178 & -0.59987 & & -0.00149 & -0.39619 & \\
\hline-10 & 0.00130 & 0.53608 & & 0.00166 & 0.57644 & & 0.00016 & 0.03674 & \\
\hline-9 & -0.00072 & -0.34389 & & 0.00073 & 0.30464 & & -0.00536 & -1.30835 & \\
\hline-8 & 0.00165 & 0.58946 & & 0.00215 & 0.61314 & & 0.00005 & 0.01515 & \\
\hline-7 & 0.00099 & 0.40453 & & -0.00012 & -0.04221 & & 0.00456 & 0.98275 & \\
\hline-6 & 0.00083 & 0.35136 & & 0.00208 & 0.74378 & & -0.00318 & -0.74343 & \\
\hline-5 & 0.00735 & 3.06215 & $* * *$ & 0.00555 & 2.00662 & $* * *$ & 0.01311 & 2.75225 & $* * *$ \\
\hline-4 & 0.02571 & 6.45806 & $* * *$ & 0.02683 & 5.42256 & $* * *$ & 0.02212 & 4.08853 & $* * *$ \\
\hline-3 & 0.00479 & 1.52520 & $*$ & 0.00592 & 1.60263 & $* *$ & 0.00115 & 0.19615 & \\
\hline-2 & -0.00236 & -0.85163 & $* * *$ & -0.00363 & -1.23095 & $* * *$ & 0.00172 & 0.25173 & \\
\hline-1 & 0.00292 & 1.20863 & $* * *$ & 0.00066 & 0.25806 & $* * *$ & 0.01019 & 1.70400 & $* *$ \\
\hline $\mathbf{0}$ & -0.00891 & -3.05103 & $* * *$ & -0.00682 & -2.18268 & $* * *$ & -0.01562 & -2.20302 & $* * *$ \\
\hline 1 & -0.00440 & -1.92831 & $* * *$ & -0.00822 & -3.25201 & $* * *$ & 0.00786 & 1.66042 & $*$ \\
\hline 2 & -0.00356 & -1.72022 & $* * *$ & -0.00244 & -1.04845 & & -0.00713 & -1.59815 & $*$ \\
\hline 3 & -0.00378 & -1.84524 & $* * *$ & -0.00362 & -1.54251 & $*$ & -0.00429 & -1.01109 & \\
\hline 4 & 0.00471 & 2.28923 & $* * *$ & 0.00443 & 1.92815 & $* * *$ & 0.00558 & 1.22171 & \\
\hline 5 & -0.00215 & -1.18348 & & -0.00121 & -0.56357 & & -0.00515 & -1.58317 & $*$ \\
\hline 6 & 0.00088 & 0.43512 & & 0.00060 & 0.28792 & & 0.00178 & 0.33433 & \\
\hline
\end{tabular}




\begin{tabular}{|l|l|l|l|l|l|l|l|l|l|}
\hline 7 & -0.00091 & -0.43351 & & -0.00205 & -0.98197 & & 0.00273 & 0.46536 & \\
\hline 8 & 0.00256 & 1.12707 & & 0.00161 & 0.66645 & & 0.00561 & 0.99514 & \\
\hline 9 & 0.00024 & 0.11518 & & -0.00050 & -0.22544 & & 0.00261 & 0.48726 & \\
\hline 10 & 0.00102 & 0.48234 & & -0.00035 & -0.16454 & & 0.00544 & 0.95767 & \\
\hline 11 & 0.00005 & 0.02537 & & -0.00003 & -0.01653 & & 0.00030 & 0.07515 & \\
\hline 12 & -0.00038 & -0.19462 & & -0.00190 & -0.84860 & & 0.00449 & 1.14970 & \\
\hline 13 & 0.00051 & 0.20703 & & 0.00371 & 1.27875 & & -0.00978 & -2.35496 & $* * *$ \\
\hline 14 & -0.00071 & -0.28092 & & -0.00005 & -0.01501 & & -0.00283 & -0.89875 & \\
\hline 15 & 0.00150 & 0.56050 & & 0.00201 & 0.64729 & & -0.00013 & -0.02496 & \\
\hline 16 & -0.00268 & -1.15754 & & -0.00153 & -0.54886 & & -0.00636 & -1.65844 & $*$ \\
\hline 17 & -0.00030 & -0.14758 & & 0.00077 & 0.34121 & & -0.00372 & -0.85576 & \\
\hline 18 & 0.00207 & 1.03687 & & 0.00303 & 1.23100 & & -0.00104 & -0.37635 & \\
\hline 19 & 0.00102 & 0.54708 & & 0.00170 & 0.79648 & & -0.00118 & -0.31364 & \\
\hline 20 & -0.00009 & -0.03669 & & 0.00000 & -0.00147 & & -0.00037 & -0.09404 & \\
\hline 21 & -0.00234 & -1.26631 & & -0.00055 & -0.25429 & & -0.00808 & -2.41748 & $* * *$ \\
\hline 22 & 0.00167 & 0.72006 & & 0.00143 & 0.48680 & & 0.00244 & 0.93418 & \\
\hline 23 & -0.00190 & -0.86365 & & -0.00170 & -0.63970 & & -0.00253 & -0.69939 & \\
\hline 24 & -0.00030 & -0.12021 & & 0.00243 & 0.87333 & & -0.00906 & -1.65793 & $*$ \\
\hline 25 & 0.00321 & 1.33858 & & 0.00453 & 1.80188 & $* *$ & -0.00104 & -0.17069 & \\
\hline 26 & 0.00005 & 0.02027 & & 0.00035 & 0.13741 & & -0.00094 & -0.18657 & \\
\hline 27 & 0.00089 & 0.35160 & & 0.00376 & 1.23576 & & -0.00832 & -2.05329 & $* * *$ \\
\hline 28 & -0.00205 & -0.79107 & & -0.00189 & -0.58887 & & -0.00256 & -0.70418 & \\
\hline 29 & -0.00107 & -0.42676 & & -0.00103 & -0.32808 & & -0.00119 & -0.37939 & \\
\hline 30 & -0.00330 & -1.33085 & & -0.00380 & -1.21518 & & -0.00168 & -0.58588 & \\
\hline
\end{tabular}

This table shows the daily average abnormal returns during the transfer event $(-30 ; 30)$ days. We used the average of the comparable firms returns to calculate the abnormal returns. The $t-$ stat is the two-tailed cross-sectional test.

Notes: $*$ indicates significance at the $10 \%$ level, $* *$ at the $5 \%, * * *$ at the $1 \%$.

As mentioned above, the Japan Exchange Group (JPX) executes the transfers on the next trading day following one week (5 trading days) after the approval. In other terms, the significance of the positive abnormal returns around the $5^{\text {th }}$ day confirms the fact that the market starts to react positively just after the announcement of the ST. Next, the abnormal returns turn significantly negative from the transfer day itself until 5 days later.

As expected, the positive abnormal returns resulting from ST to the TSE1 were significantly larger. For instance, during the whole transfer event [-30; 30] days, the average cumulative returns CAR is significantly positive for companies that transferred to the TSE1 $(+3.74 \%)$. On the contrary, other transfers have a negative cumulative abnormal return (-4.83\%) over the same period. The graphs in Figure 1 and Figure 2 confirm these results. 
Table 4: Average Abnormal Returns tests of significance using the Market Index as Benchmark

\begin{tabular}{|c|c|c|c|c|c|c|c|c|c|}
\hline \multirow[t]{2}{*}{ Days } & \multicolumn{3}{|c|}{ All Transfers } & \multicolumn{3}{|c|}{ TSE 1} & \multicolumn{3}{|c|}{ TSE 2} \\
\hline & AAR & t-stat & Sig & AAR & t-stat & Sig & AAR & t-stat & Sig \\
\hline-30 & -0.00156 & -0.57136 & & -0.00061 & -0.17530 & & -0.00468 & -1.62522 & $*$ \\
\hline-10 & 0.00150 & 0.59370 & & 0.00345 & 1.09897 & & -0.00486 & -1.50042 & \\
\hline-9 & -0.00016 & -0.06651 & & 0.00130 & 0.46456 & & -0.00494 & -1.19671 & \\
\hline-8 & 0.00183 & 0.70697 & & 0.00240 & 0.75085 & & -0.00002 & -0.00404 & \\
\hline-7 & 0.00114 & 0.40297 & & -0.00081 & -0.24229 & & 0.00753 & 1.50407 & \\
\hline-6 & -0.00006 & -0.02683 & & 0.00068 & 0.26562 & & -0.00247 & -0.51150 & \\
\hline-5 & 0.00712 & 2.62282 & $* * *$ & 0.00596 & 1.87461 & $* *$ & 0.01089 & 2.12343 & $* * *$ \\
\hline-4 & 0.02336 & 5.45894 & $* * *$ & 0.02465 & 4.67078 & $* * *$ & 0.01913 & 3.15891 & $* * *$ \\
\hline-3 & 0.00420 & 1.17603 & & 0.00645 & 1.57316 & $*$ & -0.00318 & -0.44089 & \\
\hline-2 & -0.00132 & -0.42515 & & -0.00191 & -0.57718 & & 0.00061 & 0.07819 & \\
\hline-1 & 0.00143 & 0.54956 & & 0.00000 & -0.00158 & & 0.00612 & 1.00189 & \\
\hline $\mathbf{0}$ & -0.00896 & -3.03068 & $* * *$ & -0.00615 & -2.15000 & $* * *$ & -0.01817 & -2.16120 & $* * *$ \\
\hline 1 & -0.00443 & -1.82548 & $* * *$ & -0.00947 & -3.61198 & $* * *$ & 0.01206 & 2.41843 & $* * *$ \\
\hline 2 & -0.00412 & -1.80839 & $* * *$ & -0.00232 & -0.92664 & & -0.00998 & -1.93116 & $* * *$ \\
\hline 3 & -0.00437 & -1.85433 & $* * *$ & -0.00402 & -1.48605 & & -0.00552 & -1.13449 & \\
\hline 4 & 0.00481 & 2.29565 & $* * *$ & 0.00514 & 2.21289 & $* * *$ & 0.00374 & 0.77995 & \\
\hline 5 & -0.00155 & -0.70709 & & -0.00030 & -0.12096 & & -0.00564 & -1.22621 & \\
\hline 6 & 0.00010 & 0.04167 & & -0.00056 & -0.23033 & & 0.00225 & 0.35468 & \\
\hline 7 & 0.00109 & 0.49223 & & 0.00099 & 0.48757 & & 0.00140 & 0.20733 & \\
\hline 8 & 0.00244 & 1.13560 & & 0.00313 & 1.24728 & & 0.00016 & 0.03927 & \\
\hline 9 & -0.00019 & -0.08256 & & -0.00023 & -0.08871 & & -0.00005 & -0.01010 & \\
\hline 10 & 0.00117 & 0.46650 & & -0.00124 & -0.46392 & & 0.00903 & 1.47565 & \\
\hline 30 & -0.00602 & -2.10689 & $* * *$ & -0.00674 & -1.87552 & $*$ & -0.00365 & -1.10780 & \\
\hline
\end{tabular}

This table shows the daily average abnormal returns during the transfer event $(-30 ; 30)$ days. We used the market index returns to calculate the abnormal returns. The $\mathrm{t}-\mathrm{stat}$ is the two-tailed crosssectional test.

Notes: $*$ indicates significance at the $10 \%$ level, ${ }^{* *}$ at the $5 \%, * * *$ at the $1 \%$. 
Table 5: Mean of Cumulative Abnormal Returns (CAR) per event periods using the mean of comparable stocks returns

\begin{tabular}{|c|c|c|c|c|c|c|c|c|c|}
\hline \multirow[b]{2}{*}{ Event Period } & \multicolumn{3}{|c|}{ All Transfers } & \multicolumn{3}{|c|}{ TSE 1} & \multicolumn{3}{|c|}{ TSE 2} \\
\hline & Mean & t-stat & p-value & Mean & t-stat & $\mathrm{p}$-value & Mean & t-stat & $\mathrm{p}$-value \\
\hline CAR $(-10 ; 10)$ & 2.82 & 11.62 & 0 & 2.32 & 8.28 & 0 & 4.39 & 9.23 & 0 \\
\hline CAR $(-30 ; 30)$ & 1.7 & 5.46 & 0 & 3.74 & 10.08 & 0 & -4.84 & -9.07 & 0 \\
\hline CAR $(-30 ;-1)$ & 3.55 & 13.35 & 0 & 4.47 & 13.98 & 0 & 0.58 & 1.33 & 0.18 \\
\hline CAR $(-10 ;-1)$ & 4.25 & 16.31 & 0 & 4.18 & 13.24 & 0 & 4.45 & 10.7 & 0 \\
\hline $\operatorname{CAR}(-5 ;-1)$ & 3.84 & 13.18 & 0 & 3.53 & 10.21 & 0 & 4.83 & 9.37 & 0 \\
\hline CAR $(0 ; 30)$ & -1.85 & -5.95 & 0 & -0.73 & -1.93 & 0.05 & -5.42 & -11.71 & 0 \\
\hline $\operatorname{CAR}(0 ; 10)$ & -1.43 & -5.58 & 0 & -1.86 & -6.46 & 0 & -0.06 & -0.11 & 0.92 \\
\hline $\operatorname{CAR}(0 ; 5)$ & -1.81 & -7.49 & 0 & -1.79 & -6.45 & 0 & -1.87 & -3.82 & 0 \\
\hline CAR $(1 ; 10)$ & -0.54 & -2.37 & 0.02 & -1.18 & -4.7 & 0 & 1.5 & 2.93 & 0 \\
\hline $\operatorname{CAR}(1 ; 30)$ & -0.95 & -3.19 & 0 & -0.05 & -0.14 & 0.89 & -3.85 & -9.24 & 0 \\
\hline
\end{tabular}

This table depicts the cumulative abnormal returns (CAR) during sub-periods of the transfer event $(-30 ; 30)$ days. We used the average of the comparable firms returns to calculate the abnormal returns. Notes: $*$ indicates significance at the $10 \%$ level, $* *$ at the $5 \%, * * *$ at the $1 \%$.

Table 6: Mean of Cumulative Abnormal Returns (CAR) per event periods using the Market index as benchmark

\begin{tabular}{|l|c|l|c|c|c|c|c|c|c|}
\hline & \multicolumn{3}{|c|}{ All Transfers } & \multicolumn{3}{c|}{ TSE 1 } & \multicolumn{3}{c|}{ TSE 2 } \\
\hline Event Period & Mean & t-stat & p-value & Mean & t-stat & p-value & Mean & t-stat & p-value \\
\hline CAR $(-10 ; 10)$ & $2.50 \%$ & 9.2368 & 0 & $2.71 \%$ & 8.7685 & 0 & $1.81 \%$ & 3.2335 & 0.0013 \\
\hline CAR $(-30 ; 30)$ & $1.47 \%$ & 4.3649 & 0 & $4.70 \%$ & 12.225 & 0 & $-9.12 \%$ & -14.217 & 0 \\
\hline CAR $(-30 ;-1)$ & $3.61 \%$ & 12.612 & 0 & $5.01 \%$ & 14.719 & 0 & $-0.94 \%$ & -1.9273 & 0.0542 \\
\hline CAR $(-10 ;-1)$ & $3.90 \%$ & 14.293 & 0 & $4.22 \%$ & 12.829 & 0 & $2.88 \%$ & 6.4117 & 0 \\
\hline CAR $(-5 ;-1)$ & $3.48 \%$ & 10.502 & 0 & $3.52 \%$ & 8.8319 & 0 & $3.36 \%$ & 6.0516 & 0 \\
\hline CAR $(0 ; 30)$ & $-2.15 \%$ & -6.3737 & 0 & $-0.30 \%$ & -0.7578 & 0.4486 & $-8.18 \%$ & -14.670 & 0 \\
\hline CAR $(0 ; 10)$ & $-1.40 \%$ & -5.2222 & 0 & $-1.50 \%$ & -5.0054 & 0 & $-1.07 \%$ & -1.8105 & 0.071 \\
\hline CAR $(0 ; 5)$ & $-1.86 \%$ & -7.5795 & 0 & $-1.71 \%$ & -6.2458 & 0 & $-2.35 \%$ & -4.318 & 0 \\
\hline CAR $(1 ; 10)$ & $-0.51 \%$ & -2.0359 & 0.0419 & $-0.89 \%$ & -3.1998 & 0.0014 & $0.74 \%$ & 1.364 & 0.1734 \\
\hline CAR $(1 ; 30)$ & $-1.25 \%$ & -3.8282 & 0.0001 & $0.31 \%$ & 0.7861 & 0.4319 & $-6.36 \%$ & -12.756 & 0 \\
\hline
\end{tabular}

This table depicts the cumulative abnormal returns (CAR) during sub-periods of the transfer event $(-30 ; 30)$ days. We used the market index return to calculate the abnormal returns.

Notes: $*$ indicates significance at the $10 \%$ level, $* *$ at the $5 \%, * * *$ at the $1 \%$. 


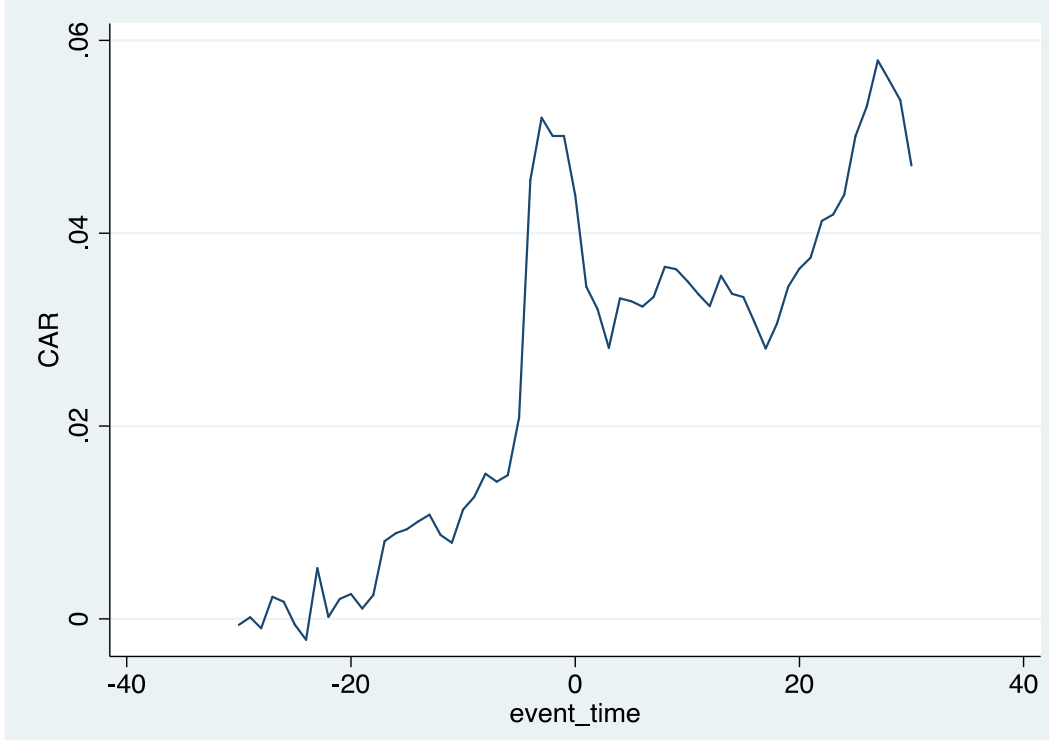

Figure 1: CAR evolution of companies that transferred to the Tokyo Stock Exchange first section (TSE 1): using the market index return as benchmark

In Table 5, the respective cumulative abnormal returns 30,10, and 5 days before the ST execution day to one day before the transfer are all significantly positive, whereby all cumulative abnormal returns from the ST execution day to 30,10, and 5 days after the transfer day are significantly negative. We obtained almost the same results using the average of comparable stocks return approach (Figure 3 and Figure 4).

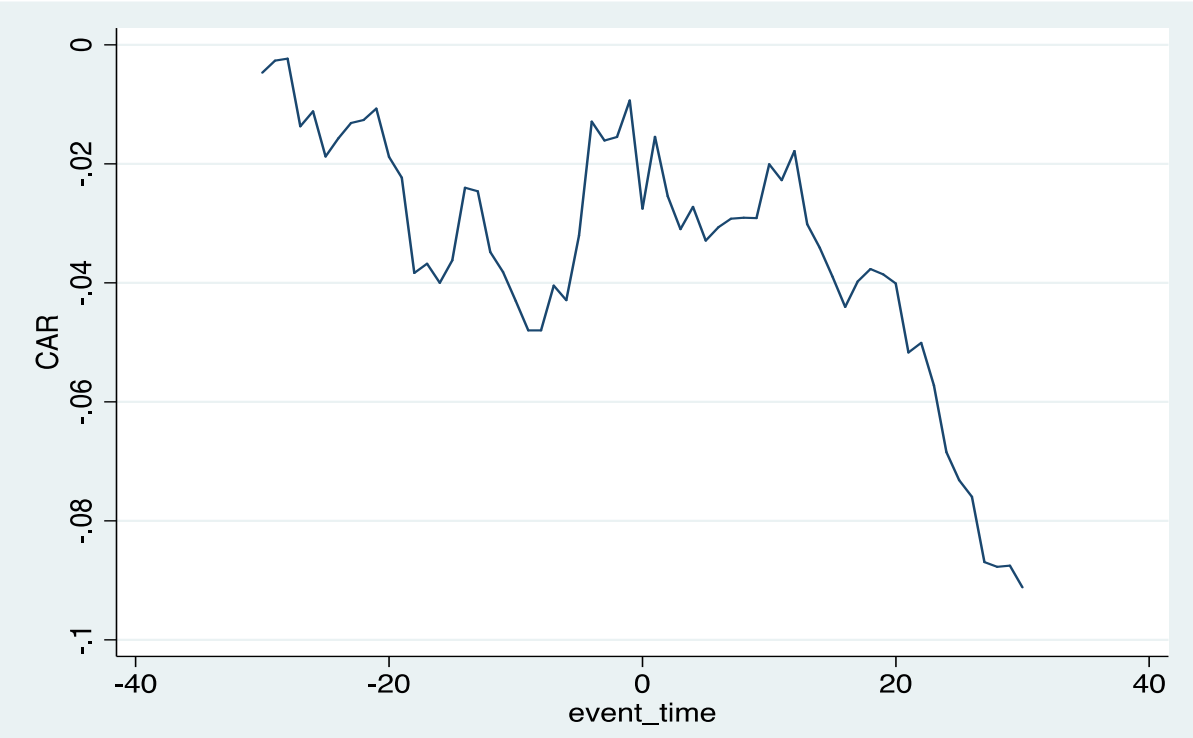

Figure 2: CAR evolution of companies that transferred to the Tokyo Stock Exchange second section (TSE 2): using the market index return as benchmark 
These findings are consistent with our hypothesis that though the market reacts positively to ST in general during the transfer event, the reaction is particularly positive a few days before the ST execution day.

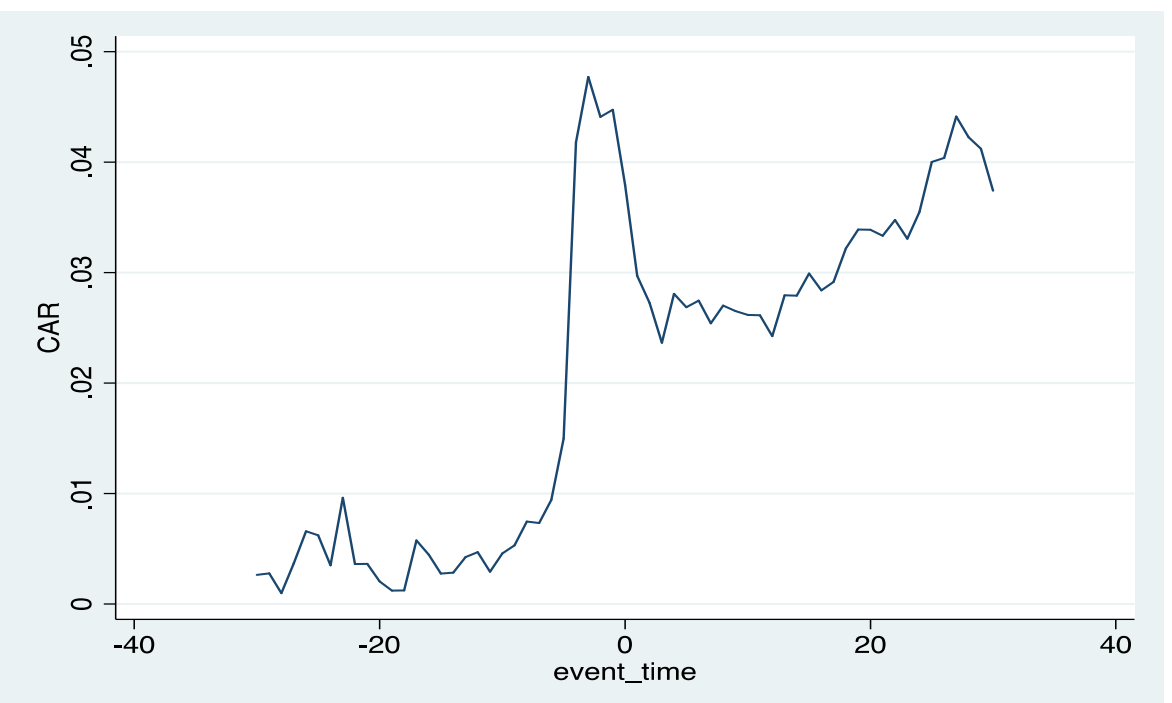

Figure 3: CAR evolution of companies that transferred to the Tokyo Stock Exchange first section (TSE 1): using the mean of comparable stocks return as benchmark

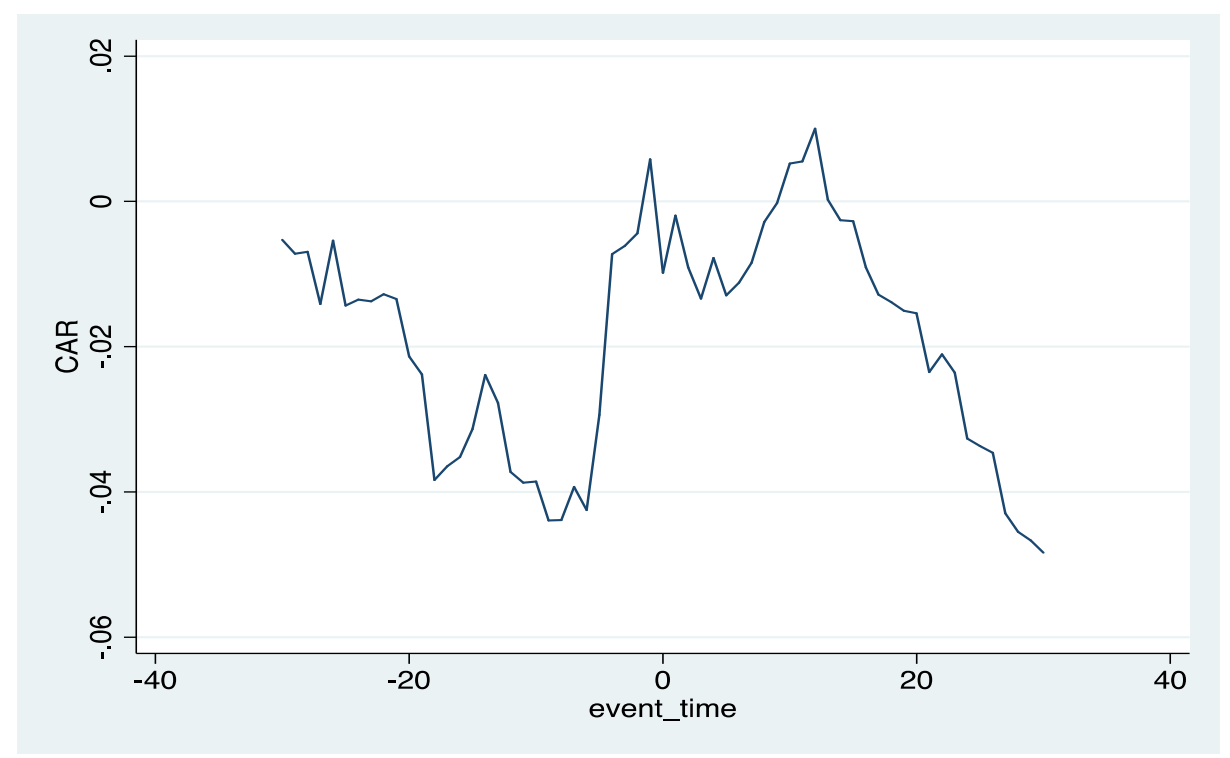

Figure 4: CAR evolution of companies that transferred to the Tokyo Stock Exchange second section TSE 2: using the mean of comparable stocks return as benchmark 


\subsection{Increase in trading activity}

We posited that ST towards the TSE 1 will change substantially the investor base level. So far, our results have demonstrated that the positive abnormal returns around the transfer day are comparatively higher for stocks that had the largest rise in terms of investor base (i.e. TSE 1). We attempt here to see whether the corresponding liquidity gains of these stocks overperform the liquidity gains of stocks that transfer to TSE 2. We use the stocks' volume ratios as Harris and Gurel (1986) to adjust for the overall market volume variation:

$V R_{i t}=\frac{V_{i t}}{V_{m t}} * \frac{V_{m}}{V_{i}}$

Where $V_{i t}$ and $V_{m t}$ are respectively the trading volumes of the stock and the total market during the transfer event; and $V_{m}$ and $V_{i}$ are the mean trading volumes of the stock and the total market 8 weeks before the transfer event. 
Table 7: Mean of Volume ratios during the transfer event using the mean of comparable stocks returns

\begin{tabular}{|c|c|c|c|c|c|c|c|c|c|}
\hline \multirow[t]{2}{*}{ Days } & \multicolumn{3}{|c|}{ All Transfers } & \multicolumn{3}{|c|}{ TSE 1} & \multicolumn{3}{|c|}{ TSE 2} \\
\hline & $\begin{array}{c}\text { Mean } \\
\text { Volume } \\
\text { Ratios } \\
\end{array}$ & t-stat & Sig & $\begin{array}{c}\text { Mean } \\
\text { Volume } \\
\text { Ratios } \\
\end{array}$ & t-stat & Sig & $\begin{array}{c}\text { Mean } \\
\text { Volume } \\
\text { Ratios } \\
\end{array}$ & t-stat & Sig \\
\hline-30 & 1.124 & 9.289 & $* * *$ & 1.247 & 8.633 & $* * *$ & 0.729 & 7.609 & $* * *$ \\
\hline-10 & 1.55 & 11.304 & $* * *$ & 1.72 & 10.922 & $* * *$ & 1.004 & 5.561 & $* * *$ \\
\hline-9 & 1.59 & 9.577 & $* * *$ & 1.768 & 9.258 & $* * *$ & 1.019 & 4.557 & $* * *$ \\
\hline-8 & 2.458 & 6.385 & $* * *$ & 2.935 & 6.334 & $* * *$ & 0.929 & 5.575 & $* * *$ \\
\hline-7 & 2.096 & 7.619 & $* * *$ & 2.357 & 7.276 & $* * *$ & 1.256 & 4.307 & $* * *$ \\
\hline-6 & 1.659 & 7.677 & $* * *$ & 1.908 & 7.378 & $* * *$ & 0.859 & 5.964 & $* * *$ \\
\hline-5 & 2.088 & 5.985 & $* * *$ & 2.272 & 5.452 & $* * *$ & 1.497 & 4.661 & $* * *$ \\
\hline-4 & 4.294 & 10.848 & $* * *$ & 4.663 & 10.308 & $* * *$ & 3.11 & 5.411 & $* * *$ \\
\hline-3 & 3.868 & 8.018 & $* * *$ & 4.44 & 7.707 & $* * *$ & 2.032 & 6.003 & $* * *$ \\
\hline-2 & 2.715 & 9.707 & $* * *$ & 2.689 & 9.932 & $* * *$ & 2.799 & 3.834 & $* * *$ \\
\hline-1 & 3.076 & 6.161 & $* * *$ & 2.934 & 6.057 & $* * *$ & 3.53 & 2.725 & $* *$ \\
\hline $\mathbf{0}$ & 3.921 & 7.588 & $* * *$ & 4.497 & 7.314 & $* * *$ & 2.074 & 4.879 & $* * *$ \\
\hline 1 & 2.47 & 6.979 & $* * *$ & 2.831 & 6.643 & $* * *$ & 1.311 & 6.428 & $* * *$ \\
\hline 2 & 2.17 & 5.974 & $* * *$ & 2.517 & 5.731 & $* * *$ & 1.059 & 6.023 & $* * *$ \\
\hline 3 & 1.852 & 12.294 & $* * *$ & 2.062 & 11.82 & $* * *$ & 1.18 & 6.735 & $* * *$ \\
\hline 4 & 1.933 & 7.618 & $* * *$ & 1.981 & 12.184 & $* * *$ & 1.778 & 1.936 & $* * *$ \\
\hline 5 & 1.667 & 14.122 & $* * *$ & 1.82 & 14.752 & $* * *$ & 1.175 & 4.744 & $* * *$ \\
\hline 6 & 1.921 & 10.372 & $* * *$ & 2.119 & 9.769 & $* * *$ & 1.285 & 6.255 & $* * *$ \\
\hline 7 & 1.735 & 12.508 & $* * *$ & 1.929 & 12.007 & $* * *$ & 1.113 & 6.935 & $* * *$ \\
\hline 8 & 2.155 & 5.557 & $* * *$ & 2.044 & 11.508 & $* * *$ & 2.511 & 1.645 & $* * *$ \\
\hline 9 & 1.782 & 10.676 & $* * *$ & 1.988 & 10.58 & $* * *$ & 1.118 & 4.374 & $* * *$ \\
\hline 10 & 1.98 & 6.953 & $* * *$ & 1.86 & 12.067 & $* * *$ & 2.364 & 2.183 & $* *$ \\
\hline
\end{tabular}

This table shows the average daily volume ratio during the transfer event $(-30 ; 10)$ days.

In Table 7, four (4) days before the execution day, the average volume ratio of companies that transferred to the TSE 1 reached four times the value of their initial average volume ratio. This is not the case for other transfers. These outcomes are consistent with our early findings showing the peak and significance of the positive abnormal returns four (4) days before the transfer. It also provides evidence of a demand shock resulting from a large addition of institutional investors such as index-funds dealing mainly with stocks listed on the TSE1. Otherwise, once the ST are approved these new investors anticipate and engage in a race to acquire the stocks before their expected rise in prices. 


\subsection{Change in investor base and economic consequences}

As discussed above, the motivation of this paper is to investigate the effect of change in investor base due to ST on the stocks' prices. Though our early results already confirm a substantial part of our expectations, we found it necessary to construct the following model which also considers firms related and market-related control variables:

$$
\begin{aligned}
& C A R_{i}=\alpha+\beta_{0} I N V_{-} B A S E_{i}+\beta_{1} M V R_{i}+\beta_{2} T O P I X_{i}+\beta_{3}\left(I N V_{-} B A S E_{i} *\right. \\
& \left.M V R_{i}\right)+\beta_{4} S_{Z} E_{i}+\beta_{5} M / B_{i}+\beta_{6} L_{Q D D U M}+\varepsilon_{i}
\end{aligned}
$$

The dependent variable is the cumulative abnormal returns (CAR) for both the pretransfer and post-transfer periods. We measured the level of change in the investor base by using our proxy INV_BASE (index inclusion) as a dummy variable that takes value 1 when the company simultaneously transfers and is added to the TOPIX index or transfer to TSE 1; and 0 for other transfers. We include the volume gains by using $M V R$ as the mean of volume ratio during the whole event and sub-event periods. TOPIX represents the overall market trend. SIZE and $M / B$ are respectively the size and the market-to-book ratio of the companies before the transfer event [$250 ;-31]$ days. We ranged the liquidity level of companies before the event by using LIQDUM as the dummy variable that takes value 1 for high-liquid companies and 0 for low-liquid companies. 
Table 8: Cross-sectional regression analysis of Cumulative Abnormal Returns (CAR) 10 days before the transfer day and from the transfer day to 10 days after

\begin{tabular}{|c|c|c|c|c|c|c|}
\hline $\begin{array}{c}\text { Independent } \\
\text { Variables }\end{array}$ & \multicolumn{2}{|c|}{ CAR [-10; 10] } & \multicolumn{2}{c|}{ CAR [-10; -1] } & \multicolumn{2}{c|}{ CAR [0; 10] } \\
\hline & $\begin{array}{c}\text { Using the } \\
\text { Market } \\
\text { Index } \\
\text { return }\end{array}$ & $\begin{array}{c}\text { Using the } \\
\text { Comparable } \\
\text { Stocks } \\
\text { average } \\
\text { returns }\end{array}$ & $\begin{array}{c}\text { Using the } \\
\text { Market Index } \\
\text { return }\end{array}$ & $\begin{array}{c}\text { Using the } \\
\text { Comparabl } \\
\text { e Stocks } \\
\text { average } \\
\text { returns }\end{array}$ & $\begin{array}{c}\text { Using the } \\
\text { Market Index } \\
\text { return }\end{array}$ & $\begin{array}{c}\text { Using the } \\
\text { Comparable } \\
\text { Stocks } \\
\text { average } \\
\text { returns }\end{array}$ \\
\hline Intercept & $-.74507^{* * *}$ & $-.597160^{* *}$ & .1602304 & .4204306 & $-0.625^{*}$ & $-.62818^{* * *}$ \\
\hline INV_BASE & $.0365051^{*}$ & $.0088707^{*}$ & $.160582^{* * *}$ & $.162291 * * *$ & -0.001 & -.0108818 \\
\hline MVR & .0298481 & .0197946 & $.0295089^{* *}$ & $.0286643^{*}$ & $0.031^{* * *}$ & $.029596^{* * *}$ \\
\hline Topix & -1.670886 & $-13.5849^{* *}$ & -5.437144 & $-26.879 * * *$ & -2.695 & $-9.1966^{* * *}$ \\
\hline Incdumm*MVR & -.0292795 & -.0185754 & $.0357709^{* *}$ & $.034709^{* *}$ & $-0.024^{* * *}$ & $-.02253^{* * *}$ \\
\hline Size & $-.03374 * * *$ & $.02855^{* *}$ & -.006332 & -.0175504 & $0.026^{* * *}$ & $.026137^{* * *}$ \\
\hline Market-to-book & -.0016053 & -.0004402 & $-.003968^{*}$ & -.0025381 & 0.001 & .0002886 \\
\hline Liqdumm & $-.07368^{* * *}$ & $-.08332^{* * *}$ & $-.09924^{* * *}$ & $-.10109^{* * *}$ & -0.025 & -.0233224 \\
\hline Adjusted R & 0.117 & 0.151 & 0.113 & 0.144 & 0.136 & 0.192 \\
\hline F-Statistic & 3.228 & 4.448 & 3.172 & 4.234 & 7.472 & 9.156 \\
\hline p-value & 0.003 & 0.000 & 0.004 & 0.000 & 0.000 & 0.000 \\
\hline Sample Size & 181 & 181 & 181 & 181 & 181 & 181 \\
\hline
\end{tabular}

Notes: $*$ indicates significance at the $10 \%$ level, ${ }^{* *}$ at the $5 \%,{ }^{* * *}$ at the $1 \%$.

Barberis et al. (2002) in their paper identified that the comovement of stocks arises when stocks are part of the same habitat. They argued that stocks' habitats constitute the stocks' categories and their investors' clienteles. And these stock habitats significantly affect the stock returns. Similarly, we assessed whether the price impact caused by ST is the same for firms that transferred to the TSE 1 and firms that transferred to the TSE 2.

We restricted our event period to ten (10) days before the ST execution day (pretransfer) and (10) days after (post-transfer) the ST execution day because this is the period in which the abnormal returns are mostly significant (Table 3 and Table 4). We start the post-transfer period from day 0 itself because this is the exact day at which abnormal returns turn significantly negative. The dependent variable is the cumulative abnormal returns $C A R$ for both the pre-transfer and post-transfer periods. We measured the level of change in investor base by using our proxy INV_BASE (index inclusion) as a dummy variable that takes value 1 when the company simultaneously transfer and is added to the TOPIX index while transferring to TSE 1 ; and 0 for other transfers. We include the volume gains by using $M V R$ as the mean volume ratio during the whole event and sub-event periods. TOPIX represents the overall market trend. SIZE and $M / B$ are respectively the size and the market-to-book ratio of the companies before the transfer event $[-250 ;-31]$ days. We ranged the liquidity level of companies before the event by using LIQDUM as the dummy variable that takes value 1 for high-liquid companies and 0 for low-liquid companies. 
In Table 8, our results suggest that the market reaction in the pre-event period [-10; -1] is significant and higher for ST towards the TSE1. The rise in the volume ratio of these companies is correlated with the rise in abnormal returns. Using the comparable sample to compute the abnormal returns, we found a similar positive relationship between the CAR and the volume ratio for the same group of companies. Since the shift in investor base is much larger for these stocks, it strongly supports our hypotheses as they encountered a much higher increase in stock prices and volumes. The relationship with the overall market trend was significantly negative, confirming the abnormal effect of ST on stock prices. Like previous studies, we found strong evidence that low-liquid companies have much higher positive abnormal returns in the pre-transfer period (Cisse and Fontaine, 2015; Lamba and Ariff, 1997; Campbell and Tabner, 2014).

After the ST execution day $[0 ; 10]$, we observe no significant difference in the behavior of abnormal returns for both ST groups consistent with the EMH. In Table 5 , the CAR after the ST execution day was on the average negative for all companies. Here, the trading volumes after the transfer day are positively correlated with the CAR. This suggests a proportional decrease in the trading volumes after the transfer. However, the current results demonstrate a persistent increase in trading volumes for ST to the TSE 1. It is unlikely to conclude that the downward trend in CAR is significant for all transferred stocks. Otherwise, this may suggest that some stocks, still maintain their increased liquidity levels even after the ST execution day. For instance, looking at the SIZE explanatory variable, small firms seem more to follow the downward trend. In other words, larger companies that are more likely to transfer into the TSE1 may be subject to another trend. This finding is supported by the trading strategies of index-tracking funds that acquire newly added stocks, not for speculation but to remain as close as possible to the index (Nakaguma et al., 2003). In the next section, we find it interesting to investigate more on the CAR after the transfer especially for ST to the TSE 1.

\subsection{Permanent price-impact}

The prior results of our study confirm the positive relationship between the extent to which the investor base level increases and the increase in stock prices and volumes, especially during the pre-execution day period. Whether this increment in prices reverts after the event is the motive of this part of the study. If CAR after the ST execution day offsets CAR before the execution day, we can assume that the stocks are subject to temporary price pressure. In the case of the contrary, it would suggest a permanent price-impact after the transfer.

To do this, we follow the method of Kaul et al. (2000) and estimate the following cross-sectional regression with $\mathrm{T}$ taking value from the event day 0 to the $30^{\text {th }}$ day, last day of our initial event period:

$$
\operatorname{CAR}_{0-T, j}=\alpha+\beta C A R_{(-5)-(-1), j}+\varepsilon_{0-T, j}
$$


$C A R_{0-T, j}$ represents the cumulative abnormal return from the transfer execution day to day $+\mathrm{T}$, until 30 days after the transfer. $\operatorname{CAR}_{(-5)-(-1), j}$ is the cumulative abnormal returns between 5 days and 1 day before the transfer. We used the market index return to calculate the abnormal returns.

We chose the transfer day (day 0 ) as our statistics show clearly that the positive abnormal returns turn negative from the ST execution day itself. Also, we consider the explanatory CAR variable between the 5 days and one day before the event as we noticed that this is the period where the increase in positive abnormal returns is significant. We also assume like other previous studies that if price pressures exist, it would be noticeable 30 days after the transfer day. To check the full reversal, we test whether $\beta=-1$ during our event. We addressed the potential effect of outliers by using a robust MM regression instead of truncation, winsorization, or any other methods because it is an appropriate statistical method to handle large outliers (Hampel et al., 2011). Also, we deal with standard errors that can impede the statistical significance of our results, by imposing conditions for Beta to be statistically indistinguishable from - 1 . We only report here the findings of ST to the TSE 1. We do so as our investor base change proxy (i.e. index inclusion) has been proven to generate demand pressure due to a sudden large interest from new investors. And this is necessary to conduct such an analysis.

In Table 9, our evidence restrains us to reject the hypothesis that Beta is not significantly different from -1 . However, the nominal values of the coefficient showed nothing very close to -1 during the event. Nevertheless, to ensure the robustness of our results we extended the period to 60 days after the transfer day. We did not report it here. When we did so, we still found no evidence of a full reversal. Instead, we observed a gradual decline of the Beta nominal values. This shows that the positive abnormal returns before the ST execution day may be partially outweighed later on, but not completely reversed. It also explains the temporary decline in Figure 1. Our results seem therefore aligned with the permanent price-impact. We found similar results when we conducted robustness tests using the comparable stocks average returns as a benchmark for abnormal returns. 
Table 9: MM-Robust Regression Tests for returns reversal; CAR is computed using the Market index as benchmark

\begin{tabular}{|c|c|c|c|c|}
\hline Variable & \multicolumn{5}{|c|}{ MM Robust regression } \\
\hline & Intercept & Beta & p-value $(\boldsymbol{\beta}=\mathbf{0})$ & p-value $(\boldsymbol{\beta}=-\mathbf{1})$ \\
\hline$[0-0, \mathrm{i}]$ & 0.0009525 & 0.842728 & 0.0000 & 0.0000 \\
\hline$[0-1, \mathrm{i}]$ & 0.0001712 & 0.6452906 & 0.0000 & 0.0000 \\
\hline$[0-2, \mathrm{i}]$ & 0.0030644 & 0.5682773 & 0.0000 & 0.0000 \\
\hline$[0-3, \mathrm{i}]$ & 0.0030644 & 0.5682772 & 0.0000 & 0.0000 \\
\hline$[0-4, \mathrm{i}]$ & 0.0054909 & 0.5734931 & 0.0000 & 0.0000 \\
\hline$[0-5, \mathrm{i}]$ & 0.009624 & 0.5070739 & 0.0001 & 0.0000 \\
\hline$[0-6, \mathrm{i}]$ & 0.0138625 & 0.4488313 & 0.0001 & 0.0000 \\
\hline$[0-7, \mathrm{i}]$ & 0.0166697 & 0.4070655 & 0.0001 & 0.0000 \\
\hline$[0-8, \mathrm{i}]$ & 0.0181173 & 0.4003968 & 0.0000 & 0.0000 \\
\hline$[0-9, \mathrm{i}]$ & 0.0220079 & 0.3646129 & 0.0001 & 0.0000 \\
\hline$[0-10, \mathrm{i}]$ & 0.0239982 & 0.3396275 & 0.0000 & 0.0000 \\
\hline$[0-11, \mathrm{i}]$ & 0.0228214 & 0.3408888 & 0.0000 & 0.0000 \\
\hline$[0-12, \mathrm{i}]$ & 0.0227067 & 0.3309143 & 0.0000 & 0.0000 \\
\hline$[0-13, \mathrm{i}]$ & 0.023285 & 0.3373757 & 0.0000 & 0.0000 \\
\hline$[0-14, \mathrm{i}]$ & 0.0222845 & 0.3158728 & 0.0000 & 0.0000 \\
\hline$[0-15, \mathrm{i}]$ & 0.0212125 & 0.3125409 & 0.0000 & 0.0000 \\
\hline$[0-16, \mathrm{i}]$ & 0.019461 & 0.3099046 & 0.0000 & 0.0000 \\
\hline$[0-17, \mathrm{i}]$ & 0.0200765 & 0.3107058 & 0.0000 & 0.0000 \\
\hline$[0-18, \mathrm{i}]$ & 0.01997 & 0.3079932 & 0.0000 & 0.0000 \\
\hline$[0-19, \mathrm{i}]$ & 0.0207745 & 0.3051677 & 0.0000 & 0.0000 \\
\hline$[0-20, \mathrm{i}]$ & 0.0216906 & 0.2814306 & 0.0000 & 0.0000 \\
\hline$[0-21, \mathrm{i}]$ & 0.0214801 & 0.268178 & 0.0000 & 0.0000 \\
\hline$[0-22, \mathrm{i}]$ & 0.0227377 & 0.2517866 & 0.0000 & 0.0000 \\
\hline$[0-23, \mathrm{i}]$ & 0.021313 & 0.2509747 & 0.0000 & 0.0000 \\
\hline$[0-24, \mathrm{i}]$ & 0.0202909 & 0.2359612 & 0.0000 & 0.0000 \\
\hline$[0-25, \mathrm{i}]$ & 0.020059 & 0.2273745 & 0.0000 & 0.0000 \\
\hline$[0-26, \mathrm{i}]$ & 0.0198036 & 0.2294721 & 0.0000 & 0.0000 \\
\hline$[0-27, \mathrm{i}]$ & 0.0212041 & 0.2112269 & 0.0000 & 0.0000 \\
\hline$[0-28, \mathrm{i}]$ & 0.0201391 & 0.1957059 & 0.0000 & 0.0000 \\
\hline$[0-29, \mathrm{i}]$ & 0.0195202 & 0.1840091 & 0.0000 & 0.0000 \\
\hline$[0-30, \mathrm{i}]$ & 0.0187961 & 0.1730633 & 0.0000 & 0.0000 \\
\hline & & & & \\
\hline
\end{tabular}

This table presents the tests for the post-transfer returns reversal for companies that transfer to the TSE 1. From the following regression:

$C_{A R_{0-T, j}}=\alpha+\beta C A R_{(-5)-(-1), j}+\varepsilon_{0-T, j}$, this table shows the MM robust regression coefficient estimate. 


\section{Conclusion}

ST to a more regulated section involves the transfer of stocks from one section to another section, and these sections often have large differences in terms of investor base level. Companies in a quest for more visibility and liquidity might opt primarily for sections that will mostly increase their investor base if they can afford it. In this paper, we investigate the economic consequences of this shift in the investor base level. We found that the extent to which the investor base shift due to ST is a key determinant of the surge in stock prices and trading volumes. If the investor interests in the stocks (i.e. investor base) increase considerably like it was the case for companies that transfer to top section TSE1 of the JPX, the increment in prices and volumes are comparatively larger than any other ST. We argue that large institutional investors dealing in more regulated/prestigious sections, once informed of the ST, join the existing investor base and engage in a race to buy these stocks at a discounted price before their anticipated rise. We also address the behavior of such an upsurge after the transfer day to examine whether it is temporary or has a permanent price-impact. We found that not only prices increase before the ST but a large portion of such increment remains. This is inconsistent with the price pressure hypothesis. In other terms, ST might positively change the stock investor base level and permanently impact the stock prices.

Finally, our results have implications for both regulators and companies' boards. For example, many regulators strive to increase market liquidity. By encouraging ST to more regulated sections, this goal can be achieved. Nevertheless, they should keep on ensuring that the quality of these top sections is maintained through stringent requirements. Of course, companies should also be aware of the positive economic consequences, especially the permanent price-impact caused by ST on their stocks, and endeavor to transfer until they reach the section that maximizes their investor base in their respective stock exchange.

ACKNOWLEDGEMENTS: The author is grateful to JC, Pr. Ohta and all members of the seminar who gave helpful comments for improving this paper. $\mathrm{He}$ is also grateful to his parents and spouse for their undeniable support. 


\section{References}

[1] Amihud, Y and Mendelson, H. (1986) 'Asset pricing and bid-ask spread', Journal of Financial Economics, Vol. 17, pp.223-249.

[2] Ankit Jain., Prasanna Tantri, and Ramabhadran S. Thirumalai. (2019) 'Demand curves for stocks do not slope down: Evidence using an exogenous supply shock', Journal of Banking and Finance, Vol. 104, pp.19-30

[3] Bagwell, L.S. (1991) 'Shareholder heterogeneity: evidence and implications', American Economic Review, Vol.81 No.2, pp.218-221.

[4] Bagwell, L.S. (1992) 'Dutch auction repurchases: an analysis of shareholder heterogeneity', Journal of Finance, Vol.47 No.1, pp.71-105.

[5] Baker, H. K., and Edelman, R. B. (1990) 'OTC market switching and stock returns: some empirical evidence', Journal of Financial Research, Vol.13 No.4, pp.325-337.

[6] Barberis, N., Shleifer, A., and Wurgler, J. (2005) 'Comovement', Journal of Financial Economics Vol.75, pp.283-317.

[7] Campbell, K and Tabner, I. T. (2014) 'Bonding and the agency risk premium: An analysis of migrations between the AIM and the Official List of the London Stock Exchange', Journal of International Financial Markets Institutions and Money, Vol.30, pp.1-20.

[8] Carhart, M. M. (1997) 'On persistence in mutual fund performance', Journal of Finance, Vol.52 No1, pp.57-82.

[9] Chemmanur, T. J., Fulghieri, P., 1999. A theory of the going-public decision. Review of Financial Studies 12 (2), 249.

[10] Cissé, A.K., Fontaine, P. (2015) 'Consequences of voluntary stock exchange section switching on stocks price, liquidity and volatility', Bank Markets Investment, Vol.136, pp.42-62.

[11] Fama, E. F, and French, K. R. (1992) 'The cross-section of expected stock returns', Journal of finance, Vol.47 No2, pp.427-465.

[12] Fama, E. F, and Kenneth, R. (1993) 'The cross-section of expected stock returns', Journal of Finance, Vol.47, 427-465.

[13] Fama, E. F and French, K. R. (1995) 'Size and book-to-market factors in earnings and returns', Journal of Finance, Vol.50 No1, pp.131-155.

[14] Harris, L, and Gurel, E. (1986) 'Price and volume effects associated with changes in the S\&P 500 list: new evidence for the existence of price pressures', Journal of Finance, Vol.41, pp.815-829.

[15] Hattangadi, A and Kelkar, S. (2016) 'What no one told you about passive investing', Investment Management Morgan Stanley, 8498721_CH_0216.

[16] Jain, P. C. (1987) 'The Effect on Stock Price of Inclusion in or Exclusion from the S\&P 500', Journal of Financial Analysts, Vol. 43, No. 1, pp.58-65.

[17] Kadlec, G, and McConnell, J. (1994) 'The effect of market segmentation and illiquidity on asset prices: evidence from exchange listings', Journal of Finance, Vol.49, pp.611-636. 
[18] Kalay, A., Sade, O., Wohl, A. (2004) 'Measuring stock illiquidity: an investigation of the demand and supply schedules at the TASE, Journal of Financial Economics, Vol.74 No.3, pp.461-486.

[19] Kasch, M and Sarkar, A. (2011) 'Is There an S\&P 500 Index Effect?' New York: Federal Reserve Bank of New York Staff Reports.

[20] Kaul, A., Mehrotra, V., Morck, R. (2000) 'Demand curves for stocks do slope down: new evidence from an index weights adjustment', Journal of Finance, Vol.55 No.2, pp.893-912.

[21] King, Michael R., and Dan Segal. (2009), 'The Long-Term Effects of CrossListing, Investor Recognition, and Ownership Structure on Valuation', The Review of Financial Studies, Vol.22, pp.2393-2421.

[22] Lamba, A.S and Ariff, M. (1997) 'The information content of firms switching from section 2 to section 1 of the Tokyo stock exchange', Pacific-Basin Finance Journal, Vol.5, pp.441-463.

[23] Merton, R. (1987) 'Presidential address: a simple model of capital market equilibrium with incomplete information', Journal of Finance Vol.42, pp.483510.

[24] Nakaguma, Y and Ishii, F. (2003) 'Abnormal Returns on New Additions to TOPIX-From the perspective of an Index Fund Manager', The Security Analysts Association of Japan.

[25] Petajisto, Antti. 2011. The index premium and its hidden cost for index funds. Journal of Empirical Finance 18 (2) (3): 271-88.

[26] Schultz, Paul. 2008. Downward-sloping demand curves, the supply of shares, and the collapse of internet stock prices. Journal of Finance 63 (1) (02): 35178.

[27] Shleifer, A. (1986) 'Do Demand Curves for Stocks Slope Down?', Journal of Finance, Vol.41, pp.579-590.

[28] Uno, J., Shibata., M., Shimatabi, T., Shimizu, T. (2004) 'Listing change and stock price: Impact of Shareholder diversification and changes in liquidity', Bank of Japan Working Paper Series, No.04-E-15. 